\title{
HIV infection in Eastern and Southern Africa: Highest burden, largest challenges, greatest potential
}

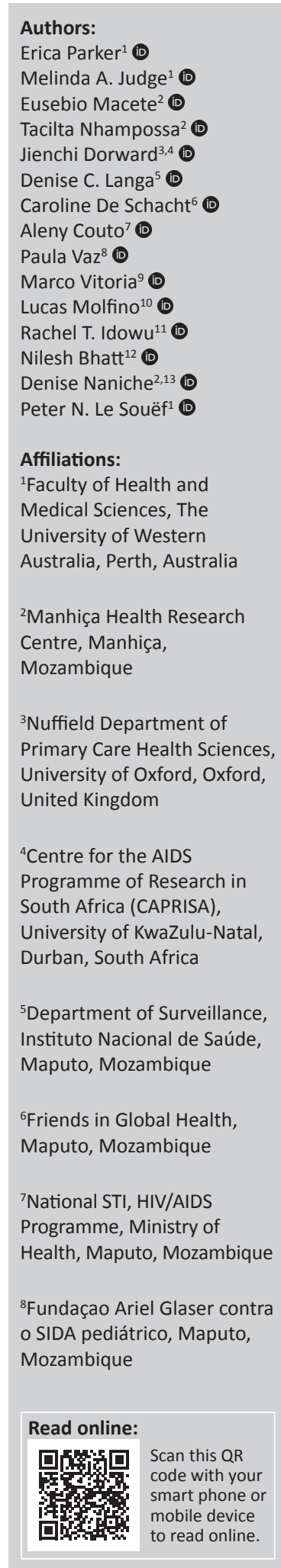

Background: The burden of HIV is especially concerning for Eastern and Southern Africa (ESA), as despite expansion of test-and-treat programmes, this region continues to experience significant challenges resulting from high rates of morbidity, mortality and new infections. Hard-won lessons from programmes on the ground in ESA should be shared.

Objectives: This report summarises relevant evidence and regional experts' recommendations regarding challenges specific to ESA.

Method: This commentary includes an in-depth review of relevant literature, progress against global goals and consensus opinion from experts.

Results: Recommendations include priorities for essential research (surveillance data collection, key and vulnerable population education and testing, in-country testing trials and evidence-based support services to improve retention in care) as well as research that can accelerate progress towards the prevention of new infections and achieving ambitious global goals in ESA.

Conclusion: The elimination of HIV in ESA will require continued investment, commitment to evidence-based programmes and persistence. Local research is critical to ensuring that responses in ESA are targeted, efficient and evaluated.

Keywords: HIV epidemiology; public health; risk factors; vulnerable populations; prevention and control; early diagnosis.

\section{Introduction}

In the decades since HIV-1 first emerged, the response has been marked by strong global commitments, extensive education campaigns and the development of improved tests and life-saving antiretroviral treatments (ART) that are reaching more and more individuals. ${ }^{1}$ With evidence-based prevention and treatment strategies available, nations have united to set goals, with the end of the HIV epidemic potentially attainable by $2030 .^{2}$

One hallmark concept in the fight against HIV has been the 'know your epidemic, know your response' approach to deliver programmes in different settings. ${ }^{3}$ More than $70 \%$ of persons living with HIV (PLWH) reside in sub-Saharan Africa (SSA), where resources for healthcare are disproportionately limited. Eastern and Southern Africa (ESA), in particular, continues to record the highest rates of HIV-1 prevalence and incidence worldwide. ${ }^{4}$ In this region, knowing where and among whom the infection is spreading has been challenging, and key populations are only recently being highlighted.

A second hallmark of the fight against HIV has been the Joint United Nations Programme on HIV / AIDS (UNAIDS) 'Fast-Track' targets, whereby 90\% of PLWH should know their status,

${ }^{9}$ Department of HIV/AIDS, World Health Organization, Geneva, Switzerland

${ }^{10}$ Médecins Sans Frontières, Maputo, Mozambique

${ }^{11}$ Center for Global Health, Centers for Disease Control and Prevention, Maputo, Mozambique

${ }^{12}$ Elizabeth Glaser Pediatric AIDS Foundation, Maputo, Mozambique

${ }^{13}$ Barcelona Institute for Global Health (ISGlobal), Spain

Corresponding author: Melinda Judge, melinda.judge@research.uwa.edu.au

Dates: Received: 02 Mar. 2021 | Accepted: 01 Apr. 2021 | Published: 28 May 2021

How to cite this article: Parker EL, Judge MA, Macete E, et al. HIV infection in Eastern and Southern Africa: Highest burden, largest challenges, greatest potential. S Afr J HIV Med. 2021;22(1), a1237. https://doi.org/10.4102/sajhivmed.v22i1.1237

Copyright: (C) 2021. The Authors. Licensee: AOSIS. This work is licensed under the Creative Commons Attribution License. 
$90 \%$ of those diagnosed should receive ART and 90\% of those on ART should achieve viral suppression by 2020 ('90-90-90'). ${ }^{5}$ Despite remarkable progress towards these targets in ESA, the sheer scale of the epidemic in this region leaves much to be done. ${ }^{6}$ In the next decade, efforts must be redoubled for raised targets of 95-95-95 by 2030 . $^{7}$ Programmes on the ground have identified region-specific challenges to be overcome and lessons that should be broadly shared with ESA and potentially with many communities globally.

An important barrier preventing progress in ESA is the timely detection and treatment of acute HIV infections. The earliest stage of HIV infection is characterised by high viral loads and a high potential for onward transmission, but it is typically missed using existing testing algorithms. ${ }^{8}$ As ART coverage improves, the proportion of transmissions attributable to undiagnosed acute HIV infection increases. ${ }^{9}$ Furthermore, new HIV infections disproportionately affect key populations. ${ }^{10}$ Affordable testing solutions for acute HIV detection in high-prevalence, resource-limited settings are needed..$^{9}$

As the 2020 deadline passed, trends indicated that the 90-90-90 targets were not reached across most of ESA. ${ }^{2}$

Renewed efforts looking ahead to the 2030 UNAIDS targets of 95-95-95 will be required. To this end, a group of regional experts was invited to collate their expertise, with a view to addressing the local challenges that prevent the achievement of global goals.

\section{State of the global epidemic}

According to UNAIDS, there were an estimated 38 million PLWH worldwide at the end of 2019, with 1.7 million new infections and 690000 AIDS-related deaths that year (Figure 1$) \cdot{ }^{10}$ A successful vaccine and functional cure for HIV are yet to be developed, and lifelong ART remains the cornerstone of management.

The 2020 UNAIDS report highlights a 'prevention crisis'. ${ }^{10}$ Programmes aiming to prevent new HIV infections (such as education, barrier contraception, voluntary male medical circumcision and pre-exposure prophylaxis [PreP]) must be a priority alongside test-and-treat programmes and must appropriately target key populations and their partners, who comprise $62 \%$ of new HIV infections globally..$^{10}$

\section{HIV epidemiology in ESA}

Regional HIV epidemics look markedly different across the world and require tailored responses. In ESA, there are 20.7 million adults and children living with HIV (54\% of global HIV prevalence), ${ }^{10}$ and in $201944 \%$ of all new infections occurred here. ${ }^{10}$ Key populations make up an estimated $28 \%$ of new infections in ESA. ${ }^{10}$ In some areas,
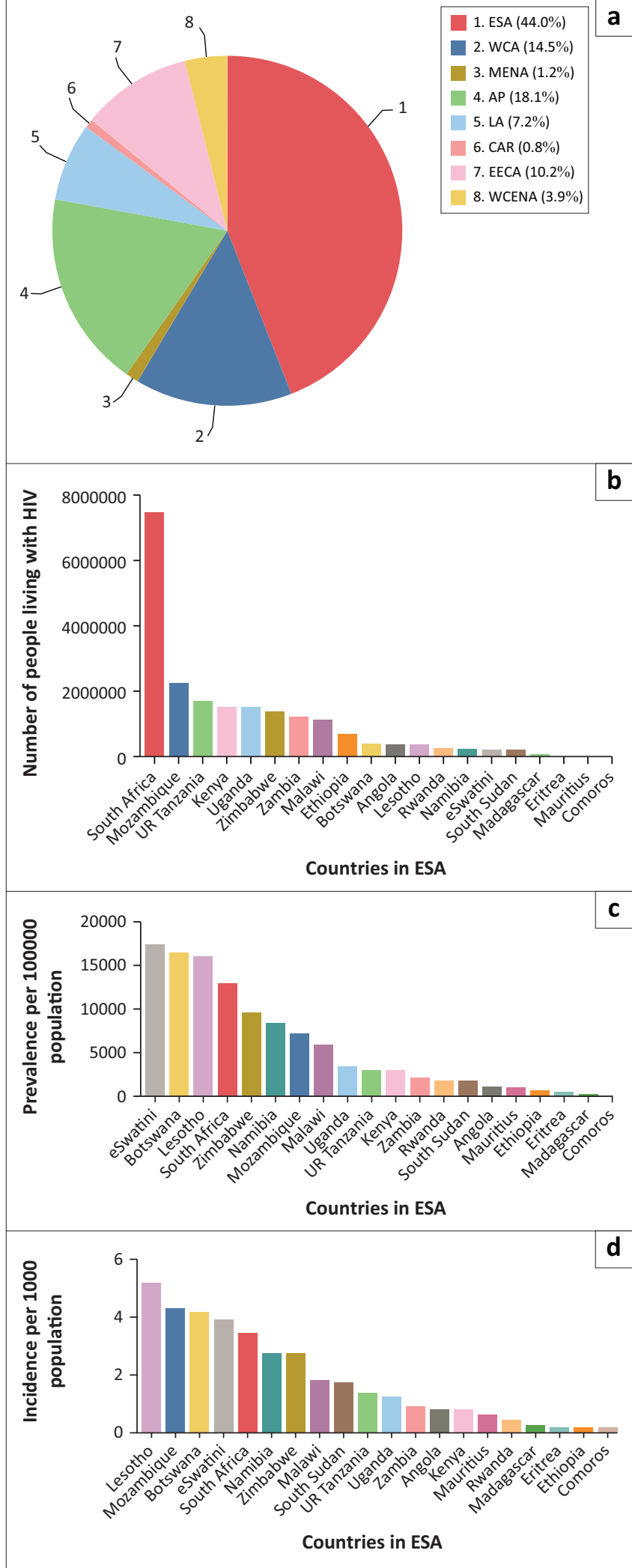

Source: All data were derived from The Joint United Nations Programme on HIV/AIDS (UNAIDS). UNAIDS Data 2020. Geneva: UNAIDS; 2020. Report No.: JC2997E; 2020 and United Nations, Department of Economic and Social Affairs, Population Division. New York, World population prospects 2019 [homepage on the Internet] [cited 2020 Aug 16]. Available from: https://population.un.org/wpp/

AP, Asia and the Pacific; CAR, Caribbean; EECA, Eastern Europe and Central Asia; ESA, Eastern and Southern Africa; LA, Latin America; MENA, Middle East and Northern Africa; WCA, Western and Central Africa; WCENA, Western and Central Europe and North America.

FIGURE 1: (a) Worldwide distribution of new HIV infections identified by UNAIDS in 2019. (b) Distribution of people living with HIV infection in ESA in 2019. (c) Prevalence of HIV infection per 100000 population among countries in ESA. (d) Incidence of HIV infection per 1000 population among countries in ESA. 


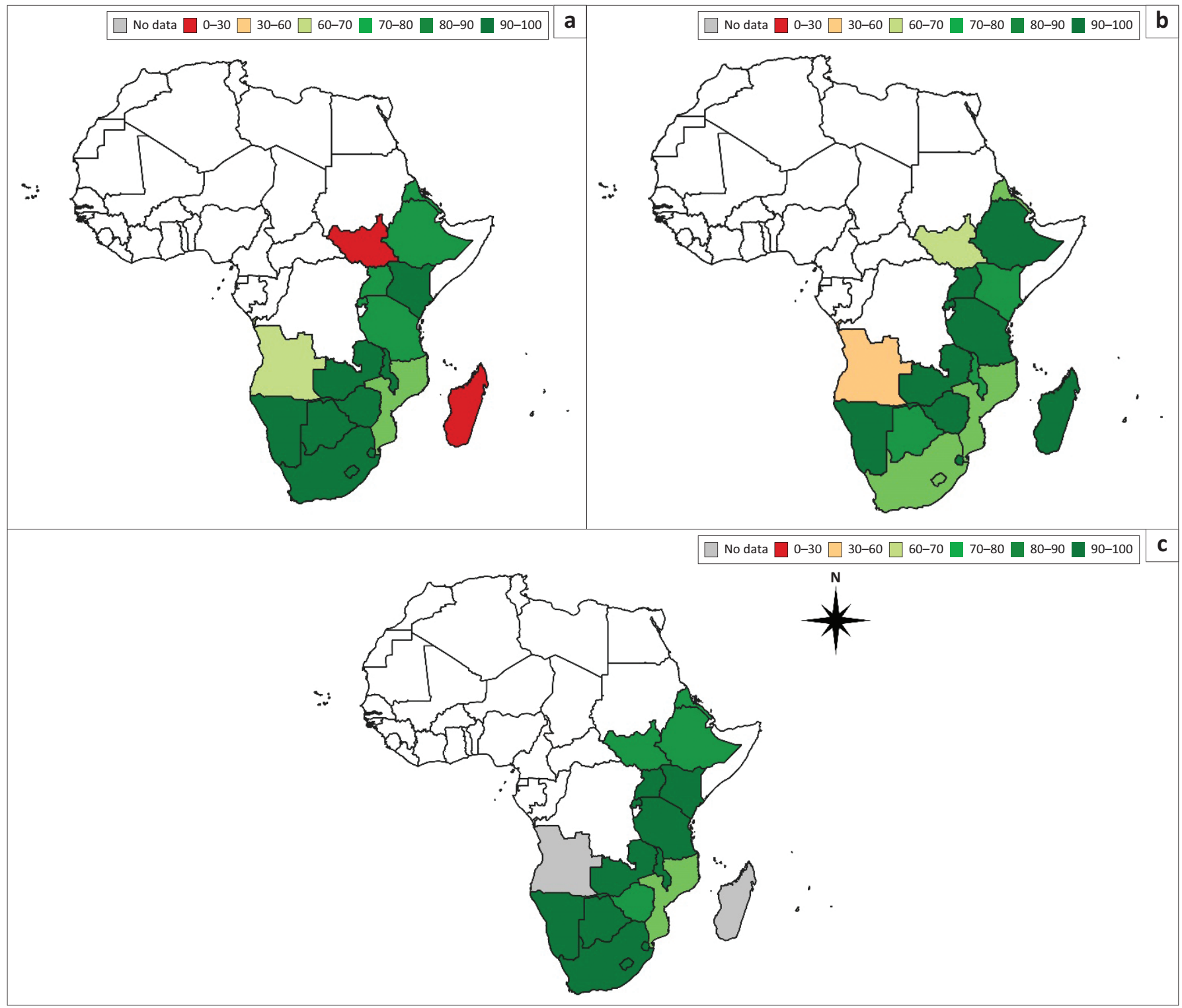

FIGURE 2: Data on the ESA 90-90-90 goals in all ages by country from the UNAIDS data 2020 report. ${ }^{10}$ (a) First 90; (b) second 90; (c) third 90.

reasonable progress has been made towards the Fast-Track targets (e.g. eSwatini, Namibia and Zambia); in other areas, progress is more limited (e.g. Mauritius and South Sudan). An estimated $87 \%$ of PLWH in ESA are aware of their status (the 'first 90'; Figure 2); however, this figure ranges from $15 \%$ to $98 \%$ between countries. ${ }^{10}$

Of those diagnosed with HIV in ESA, approximately 83\% have commenced ART (the 'second 90'). ${ }^{10}$ This figure ranges from $37 \%$ to $98 \%$ between countries, ${ }^{10}$ highlighting deep inequities within and across countries. Of those on treatment, 90\% have achieved viral suppression (the 'third 90'); this figure ranges from $68 \%$ to $97 \%$ between countries, with 2 of 21 countries unable to provide estimates. Combatting the epidemic in ESA is a multifaceted challenge, and progress must occur within a broader context of socio-economic development. Despite some successes, the 2020 milestones were not achieved in many countries across ESA, and the greatest challenges persist as the focus shifts to achieving the new 95-95-95 targets.

\section{Challenges for achieving 95-95-95 in ESA}

\section{The first 95}

In high HIV prevalence settings, obtaining accurate measures of the first 95 is challenging. In ESA, HIV care commonly takes place in rural settings, utilising paper-based records. ${ }^{11}$ To estimate the first 95, the denominator is typically the number of people testing positive for HIV during randomised household or community-based serosurveys and/or at antenatal clinics; the numerator is those among them known to have previous positive results (either disclosed to surveyors or identified in medical records). ${ }^{12}$

Rates of non-disclosure can be high. ${ }^{13}$ When people are retested in southern Mozambique, non-disclosure of previous results occurs in over one-third of people, but the rate is higher for tests performed in a community setting $(38.9 \%)$ or initiated by the provider $(29.4 \%)$ than in those presenting for voluntary testing $(13 \%){ }^{13}$ Similar findings have been 
described in Tanzania and Malawi. ${ }^{14,15}$ Cross-checking survey responses against medical records is impossible in many countries where HIV testing is performed anonymously. ${ }^{11}$ The high percentage of HIV-positive people who do not disclose, and are thus repeatedly deemed recently infected, leads to an overestimation of new HIV cases and an underestimation of progress towards the first 95. In Mozambique, non-disclosure resulted in underestimation of the first 95 by around $8.5 \% .^{13}$

Improving testing coverage to achieve the first 95 is feasible but must be accompanied by interventions that support the whole care cascade. In the Treatment as Prevention (TasP) trial of universal test-and-treat in KwaZulu-Natal, South Africa, repeated rounds of home-based testing increased the proportion of people knowing their HIV status to $91.5 \%{ }^{16}$ However, only $58.0 \%$ of these individuals commenced ART; many did not link to care. ${ }^{16}$ This suggests that to reach 95-9595, all three targets must be understood and addressed in parallel. ${ }^{17}$

\section{The second 95}

The second 95 is more readily measured, as countries (or their health facilities and non-governmental organisations) generally have stronger records on the number of people receiving ART. According to World Health Organization recommendations, early ART commencement has reduced HIV / AIDS-related mortality, with some models showing an estimated $75 \%$ fewer deaths per annum. ${ }^{18}$ Test-and-treat strategies recommending commencement of ART within 14 days of a positive diagnosis (independent of the CD4+ $\mathrm{T}$-cell count) are relatively recent in most of $\mathrm{SSA},{ }^{19}$ and uptake has been commendable. ${ }^{20}$ Broader implementation is limited not only by the political will but also by the resources required to upskill staff and provide a sustainable treatment supply. Given the scale of the epidemic in ESA, the rollout of any advances in treatment regimens to the front lines can present a formidable challenge. The system's fragility has been highlighted by COVID-19 over the past year, with reports of delays in the delivery of treatment stock from international suppliers, depleted national stockpiles and periods of lockdown limiting individuals' access to HIV medications. ${ }^{21}$

Based on country guidelines, in 2014-2015, of those eligible for ART in Manhiça, Mozambique, 83.7\% started ART within 3 months. ${ }^{22}$ In July 2016, Mozambique phased in the implementation of test-and-treat and undertook qualitative research into the patterns of ART initiation or refusal. ${ }^{23,24}$ The acceptance of treatment depends on the availability and accessibility of services, as well as appropriate and considered explanations following diagnosis. ${ }^{25}$

Linkage to care is improved by the desire to live, family support and subjective illness. ${ }^{23,24}$ Barriers to linkage to care include the fear of dissemination of one's HIV status, feeling subjectively healthy, migration, health system issues and fears of discrimination. . $^{23,24,26}$

\section{The third 95}

Achieving viral suppression requires retention in care, maintenance of ART and regular testing of the HIV viral load. Retention in care is improved by feeling better after ART initiation, confidence in the health system and support from family and providers. ${ }^{27}$ Communication about continuing treatment despite feeling better also helps. ${ }^{24}$ Barriers to retention include provider authoritarianism, which limits patient autonomy and engagement in their healthcare, and the adverse effects of ART. ${ }^{27}$ Men across the region are a hard-to-reach group; they test less, and more abandon ART after initiation..$^{22}$ There are additional complexities related to paediatric care, such as the health literacy of parents and their confidence in managing HIV. For children, retention is highest when both mother and child register concurrently. ${ }^{28}$ Innovative strategies to improve testing uptake and support early ART initiation and nutritional supplementation can improve retention. ${ }^{29,30}$

Before the introduction of the universal test-and-treat programme, there were concerns that commencing ART among people with high CD4+ T-cell counts would overburden the health system and that those feeling healthy would not adhere to treatment. ${ }^{31}$ However, of the PLWH in KwaZulu-Natal with CD4+ T-cell counts of $>500$ cells $/ \mu \mathrm{L}$, $78 \%$ accepted ART, ${ }^{32} 86 \%$ were adherent ${ }^{33}$ and $96 \%$ achieved viral suppression. ${ }^{34}$ Furthermore, retention in care and viral suppression were similar among people who initiated ART with CD4+ T-cell counts of $>500$ cells $/ \mu L$ compared to those with lower CD4+ T-cell counts. ${ }^{35}$

Measuring the third 95 requires country-wide laboratory systems capable of processing large volumes of viral load requests and returning results; thus, many ESA countries score poorly. ${ }^{10}$ For example, in Mozambique, only $45 \%$ of PLWH achieve documented viral suppression ${ }^{10}$; however, viral load testing is available to few, particularly in rural settings. ${ }^{36,37}$ Under-developed laboratory systems also delay diagnoses of virological failure, leading to increased transmission, illness progression and treatment resistance. ${ }^{38}$ Point-of-care (POC) viral load testing improved viral suppression, retention in care and the communication of results to patients in KwaZulu-Natal, ${ }^{39}$ and it proved feasible and cost-effective in Botswana and Zambia. ${ }^{40,41}$ Further development of centralised, high-throughput laboratorybased testing alongside decentralised POC testing will be crucial to ensure adequate monitoring of viral suppression throughout ESA.

\section{The impending challenge of acute HIV infections}

Acute HIV infection is commonly defined as the period prior to seroconversion, between 3 and 12 weeks in duration. ${ }^{42,43}$ Gene expression is vastly upregulated in the initial months, driving inflammation, immune responses and cell turnover. ${ }^{44}$ This correlates with a substantial peak in viral load, meaning the risk of onward transmission 
during acute HIV is 8-25 times higher than during chronic infection. ${ }^{45,46,47}$ The estimated prevalence of acute HIV infection in ESA is $1 \%-3 \%{ }^{48,49,50,51}$ Undiagnosed acute HIV is particularly concerning for the following: pregnant and breastfeeding women who have poorer health outcomes as well as increased perinatal transmission risk ${ }^{52,53,54,55}$; people who received blood transfusions screened for HIV serology but not viral load ${ }^{56,57}$; and those who started PreP when already infected, as this may confer an increased risk of drug resistance mutations. ${ }^{58}$

The earliest time period that an acute HIV infection can be detected is $5-14$ days by nucleic acid amplification..$^{59}$ This is not feasible in low-resource settings, so other options include viral load POC testing (Gene Xpert $^{60}$ and AlereQ ${ }^{61}$ ), p24 antigen testing (if developed into rapid tests), ${ }^{62}$ nonviral immune response biomarkers (e.g. IP-10) ${ }^{63}$ or a symptom/risk score. ${ }^{8,64}$ Rapid testing and ART for all HIVseropositive individuals remains the priority; however, a focus on this alone will miss seronegative HIV-infected individuals. As ART coverage increases, the proportion of HIV transmission attributable to acute HIV will increase. Affordable rapid tests for p24 or non-viral immune markers combined with a risk score may be the best way to identify acutely infected individuals in high-HIV-burden, lowresource settings.

\section{Disproportionate impact of new HIV infections on key and vulnerable populations}

Of the 1.7 million new HIV infections in $2019,62 \%$ occurred in key populations and their sexual partners. ${ }^{6}$ Key populations include men who have sex with men, ${ }^{65}$ people who inject drugs, $^{66}$ female sex workers $^{67}$ and transgender people. ${ }^{6}$ Vulnerable populations at increased HIV risk in ESA include prisoners, ${ }^{6,68}$ long-haul truck drivers, ${ }^{69}$ mobile mining workers, ${ }^{70}$ migrants ${ }^{71}$ and serodiscordant couples. ${ }^{6}$ Also at disproportionately high risk of HIV infection are young women, ${ }^{72}$ who are 2-3 times $^{73,74}$ more likely to be newly infected than their 15-24-year-old male counterparts.

Pregnant and breastfeeding women and their infants are an often-overlooked vulnerable population. ${ }^{52}$ Infants of mothers who acquired HIV during pregnancy or postpartum are at increased risk of HIV transmission compared to infants of chronically HIV-infected mothers. ${ }^{52}$

Approximately 45\% of new global infections in 2019 were in ESA. ${ }^{6,10}$ No country in ESA has sufficient data to describe the size of their key populations, ${ }^{10,75}$ although several have commenced population-specific mapping (Table 1$){ }^{76}$ Control of HIV in these populations will contribute to the deceleration of the HIV epidemic in the general population. National surveys of key populations biennially are recommended, as knowing the epidemic is the first key to design the response.

\section{Recommendations for research priorities}

- Promote and expand local prevention research, including programme and policy evaluations.

- Investigate and implement methods to improve the accessibility of HIV education and testing, including routine surveillance, particularly for key populations.

TABLE 1: Prevalence of HIV among certain key and vulnerable populations in ESA.

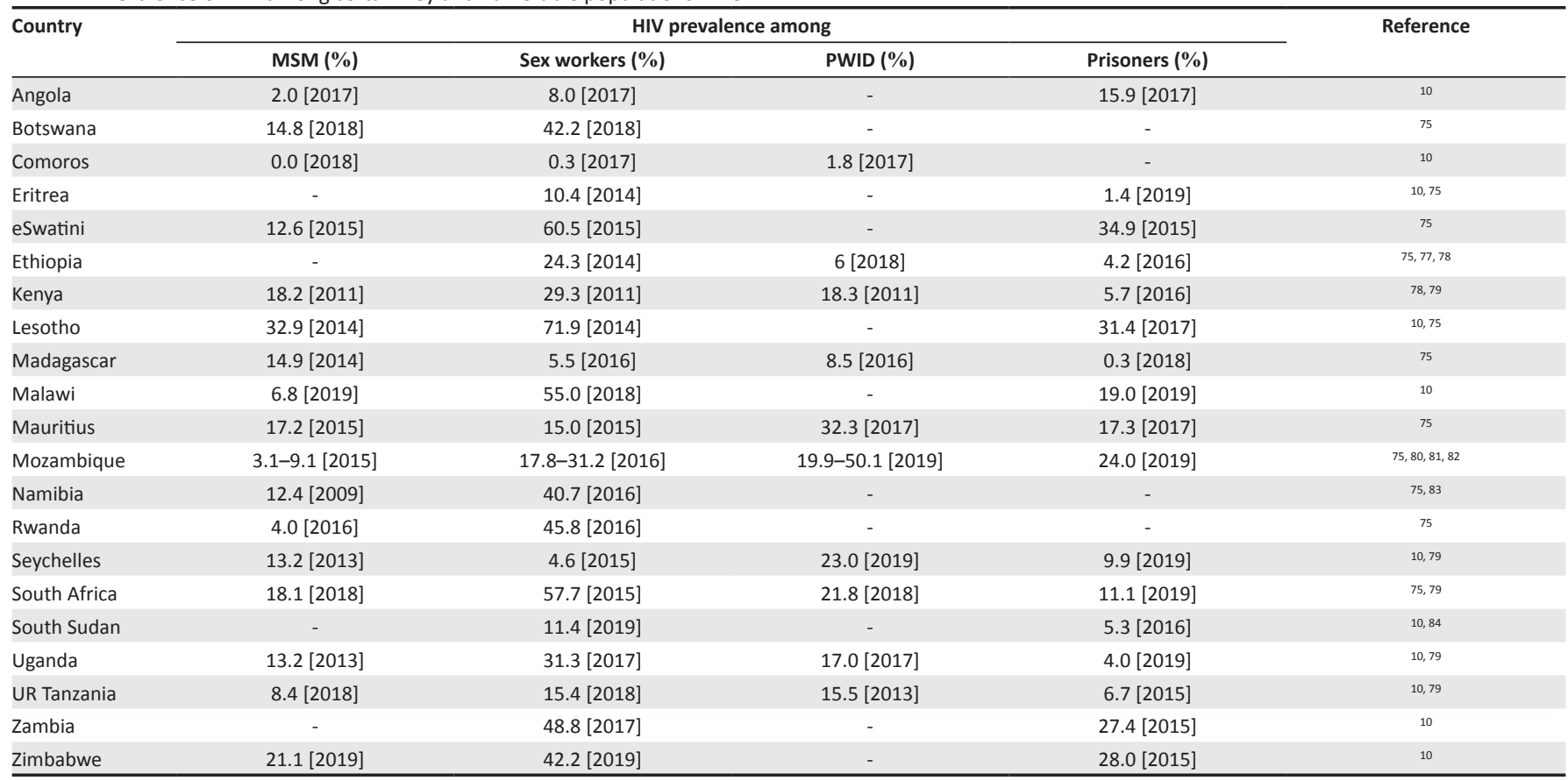

Note: Data on the HIV prevalence among transgender people are not presented in this table because of a lack of data on this key population in ESA; of the vulnerable populations, only prisoners and incarcerated people have sufficient data in ESA to be presented in this table.

MSM, men who have sex with men; PWID, people who inject drugs; [year], year of publication. 
- Support in-country trials of viral load and CD4 T-cell count POC testing and the surrounding services required to improve ART adherence, clinical management and retention in care.

\section{Conclusion}

The road to HIV elimination in ESA requires continued strong and sustained national and international investment, commitment to evidence-based programmes and persistence. The region contains over half of the world's population of PLWH and continues to have major challenges to achieving 90-90-90, let alone the looming target of 95-95-95. The priority must remain diagnosing, treating and virally suppressing all existing HIV infections. However, in high-prevalence settings, the prevention of new infections and early diagnosis of acute infections remain important goals. Research must ensure that responses in the region are targeted, efficient and evaluated. In particular, ESA will benefit from strengthened surveillance and key and vulnerable population research, incountry development and validation of HIV tests, and supported rapid transition to new ART regimens to ensure sustainable progress towards important global goals.

\section{Acknowledgements}

The authors thank Eva Kiwango, the UNAIDS country director for Mozambique, for the contribution to this article.

\section{Competing interests}

The authors declare that they have no financial or personal relationships that may have inappropriately influenced them in writing this article.

\section{Authors' contributions}

E.P. and M.J. are co-first authors and have contributed equally to the article. E.P., M.A.J., E.M., T.N., D.N. and P.N.L.S. planned and organised the collaboration; all authors contributed region-specific knowledge and expertise. E.P., M.A.J., D.N. and P.N.L.S. wrote the manuscript, with review and revision by all authors.

\section{Ethical considerations}

This article followed all ethical standards for research without direct contact with human or animal subjects.

\section{Funding information}

This study was supported by the Manhiça Foundation, Mozambique, and a Research Impact Grant (RA/1/2799/40) from the University of Western Australia.

\section{Data availability}

Publicly available data sets were accessed from https:// www.unaids.org/sites/default/files/media_asset/2020_ aids-data-book_en.pdf (associated with Figures 1 and 2) and https:/ / population.un.org/wpp/ (associated with Figure 1).

\section{Disclaimer}

The views and opinions expressed in this article are those of the authors and do not necessarily reflect the official policy or position of any affiliated agency of the authors.

\section{References}

1. Ford N, Ball A, Baggaley R, et al. The WHO public health approach to HIV treatment and care: Looking back and looking ahead. Lancet Infect Dis. 2018;18(3):e76-e86. https://doi.org/10.1016/S1473-3099(17)30482-6

2. The Joint United Nations Programme on HIV/AIDS (UNAIDS). Seizing the moment. Geneva: UNAIDS; 2020. Report No.: JC2991.

3. Wilson D, Halperin DT. "Know your epidemic, know your response": A useful approach, if we get it right. Lancet. 2008;372(9637):423-426. https://doi. org/10.1016/S0140-6736(08)60883-1

4. The Joint United Nations Programme on HIV/AIDS (UNAIDS). Global AIDS Update 2019 - Communities at the Centre. Geneva: UNAIDS; 2019. Report No: JC2956.

5. The Joint United Nations Programme on HIV/AIDS (UNAIDS). 90-90-90 An ambitious treatment target to help end the AIDS epidemic. Geneva: UNAIDS; 2014. Report No.: JC2684.

6. The Joint United Nations Programme on HIV/AIDS (UNAIDS). Miles to go: Closing gaps, breaking barriers, righting injustices. Geneva: UNAIDS; 2018. Report No.: JC2924.

7. The Joint United Nations Programme on HIV/AIDS (UNAIDS). Fast track - Ending the AIDS epidemic by 2030. Geneva: UNAIDS; 2014. Report No.: JC2686.

8. Sanders EJ, Wahome E, Powers KA, et al. Targeted screening of at-risk adults for acute HIV-1 infection in sub-Saharan Africa. AIDS. 2015;29(Suppl 3):S221-S230. https://doi.org/10.1097/QAD.0000000000000924

9. Rutstein SE, Ananworanich J, Fidler S, et al. Clinical and public health implications of acute and early HIV detection and treatment: A scoping review. J Int AIDS Soc. 2017;20(1):21579. https://doi.org/10.7448/IAS.20.1.21579

10. The Joint United Nations Programme on HIV/AIDS (UNAIDS). UNAIDS Data 2020 Geneva: UNAIDS; 2020. Report No.: JC2997E; 2020.

11. Bernardo EL, Fuente-Soro L, Lopez-Varela E, Naniche D. Anonymity in HIV testing: Implications for public health. Lancet. 2017;390(10112):2546.

12. UNAIDS Reference Group on Estimates, Modelling and Projections. Annex on methods. Geneva: UNAIDS; 2018.

13. Fuente-Soro L, Lopez-Varela E, Augusto O, et al. Monitoring progress towards the first UNAIDS target: Understanding the impact of people living with HIV who retest during HIV-testing campaigns in rural Mozambique. J Int AIDS Soc. 2018;21(4):e25095. https://doi.org/10.1002/jia2.25095

14. Rentsch CT, Reniers G, Machemba R, et al. Non-disclosure of HIV testing history in population-based surveys: Implications for estimating a UNAIDS 90-90-90 target. Glob Health Action. 2018;11(1):1553470. https://doi.org/10.1080/16549716.201 8.1553470

15. Choko AT, MacPherson P, Webb EL, et al. Uptake, accuracy, safety, and linkage into care over two years of promoting annual self-testing for HIV in Blantyre, Malawi: A community-based prospective study. PLoS Med. 2015;12(9):e1001873. https:// doi.org/10.1371/journal.pmed.1001873

16. Iwuji CC, Orne-Gliemann J, Larmarange J, et al. Universal test and treat and the HIV epidemic in rural South Africa: A phase 4, open-label, community cluster randomised trial. Lancet HIV. 2018;5(3):e116-e125.

17. Fox MP. Are we shifting attrition downstream in the HIV cascade? Lancet HIV. 2016;3(12):e554-e555. https://doi.org/10.1016/S2352-3018(16)30149-7

18. Johnson LF, May MT, Dorrington RE, et al. Estimating the impact of antiretroviral treatment on adult mortality trends in South Africa: A mathematical modelling study. PLOS Med. 2017;14(12):e1002468. https://doi.org/10.1371/journal. pmed. 1002468

19. Tymejczyk O, Brazier E, Yiannoutsos $C T$, et al. Changes in rapid HIV treatment initiation after national 'treat all' policy adoption in 6 sub-Saharan African countries: Regression discontinuity analysis. PLoS Med. 2019;16(6):e1002822. https://doi.org/10.1371/journal.pmed.1002822

20. Ford N, Vitoria M, Doherty M. Providing antiretroviral therapy to all who are HIV positive: The clinical, public health and programmatic benefits of Treat All. J Int AIDS Soc. 2018;21(2):e25078. https://doi.org/10.1002/jia2.25078

21. Jewell BL, Mudimu E, Stover J, et al. Potential effects of disruption to HIV programmes in sub-Saharan Africa caused by COVID-19: Results from multiple mathematical models. Lancet HIV. 2020;7(9):e629-e640. https://doi.org/10.1016/ S2352-3018(20)30211-3

22. Lopez-Varela E, Fuente-Soro L, Augusto OJ, et al. Continuum of HIV care in rural Mozambique: The implications of HIV testing modality on linkage and retention. J Acquir Immune Defic Syndr. 2018;78(5):527-535. https://doi.org/10.1097/ QAl.0000000000001720

23. Magaço A, Dovel K, Cataldo F, et al. 'Good health' as a barrier and facilitator to ART initiation: A qualitative study in the era of test-and-treat in Mozambique. Cult Health Sex. 2019;21(9):1059-1073. https://doi.org/10.1080/13691058.2018.153 5091

24. Nhassengo $P$, Cataldo $F$, Magaco $A$, et al. Barriers and facilitators to the uptake of test and treat in Mozambique: A qualitative study on patient and provider perceptions. PLoS One. 2018;13(12):e0205919. https://doi.org/10.1371/journal. pone.0205919 
25. Govindasamy D, Ford N, Kranzer K. Risk factors, barriers and facilitators for linkage to antiretroviral therapy care: A systematic review. AIDS. 2012;26(16):2059-2067. https://doi.org/10.1097/QAD.0b013e3283578b9b

26. Fuente-Soro L, Iniesta C, López-Varela E, et al. Tipping the balance towards longterm retention in the HIV care cascade: A mixed methods study in southern Mozambique. PLoS One. 2019;14(9):e0222028. https://doi.org/10.1371/journal. pone.0222028

27. Maixenchs $M$, Boene $H$, Anselmo $R$, et al. Post-ART symptoms were not the problem: A qualitative study on adherence to ART in HIV-infected patients in Mozambican rural hospital. PLoS One. 2015:10(9):e0137336, https://doi. org/10.1371/journal.pone.0137336

28. Nhampossa T, Fernandez S, Augusto O, et al. Discordant retention of HIV-infected mothers and children: Evidence for a family-based approach from Southern Mozambique. Medicine (Baltimore). 2020;99(32):e21410.

29. Rosen S, Maskew M, Fox MP, et al. Initiating antiretroviral therapy for HIV at a patient's first clinic visit: The RapIT randomized controlled trial. PLoS Med. 2016;13(5):e1002015. https://doi.org/10.1371/journal.pmed.1002015

30. Saghayam S, Wanke C. The impact of nutritional status and nutrition supplementation on outcomes along the HIV treatment cascade in the resourcelimited setting. Curr Opin HIV AIDS. 2015;10(6):472-476. https://doi.org/10.1097/ $\mathrm{COH} .000000000000202$

31. Geffen N, Low M. When to start antiretroviral treatment? A history and analysis of a scientific controversy. S Afr J HIV Med. 2017;18(1):a734. https://doi. org/10.4102/sajhivmed.v18i1.734

32. Garrett N, Norman E, Leask K, et al. Acceptability of early antiretroviral therapy among South African women. AIDS Behav. 2018;22(3):1018-1024. https://do . org/10.1007/s10461-017-1729-2

33. Iwuji C, McGrath N, Calmy A, et al. Universal test and treat is not associated with sub-optimal antiretroviral therapy adherence in rural South Africa: The ANRS 12249 TasP trial. J Int AIDS Soc. 2018;21(6):e25112. https://doi.org/10.1002/ jia2.25112

34. Dorward J, Drain PK, Osman F, et al. Early antiretroviral therapy is associated with better viral suppression and less HIV drug resistance after implementation of universal treatment in South Africa. AIDS Res Hum Retroviruses. 2020;36(4):297-299. https://doi.org/10.1089/AID.2019.0206

35. Dorward J, Sookrajh Y, Gate K, et al. HIV treatment outcomes among people with initiation CD4 counts $>500$ cells/ $\mu \mathrm{L}$ after implementation of Treat All in South African public clinics: a retrospective cohort study. Journal of the International AIDS Society. 2020;23(4):e25479.

36. Mozambique Ministry of Health (MISAU). 2017 annual report of activities related to HIV/AIDS. Maputo, Mozambique: MISAU; April 2018.

37. Swannet S, Decroo T, De Castro SMTL, et al. Journey towards universal viral load monitoring in Maputo, Mozambique: Many gaps, but encouraging signs. Int Health. 2017;9(4):206-214. https://doi.org/10.1093/inthealth/ihx021

38. Petersen ML, Tran L, Geng EH, et al. Delayed switch of antiretroviral therapy after virologic failure associated with elevated mortality among HIV-infected adults in virologic failure associated with elevated mortality among HIV-infected adults in
Africa. AIDS. 2014;28(14):2097-2107. https://doi.org/10.1097/QAD.00000000000 00349

39. Drain PK, Dorward J, Violette LR, et al. Point-of-care HIV viral load testing combined with task shifting to improve treatment outcomes (STREAM): Findings from an open-label, non-inferiority, randomised controlled trial. Lancet HIV. from an open-label, non-inferiority, randomised controlled trial. Lance
2020;7(4):e229-e237. https://doi.org/10.1016/S2352-3018(19)30402-3

40. Moyo S, Mohammed T, Wirth KE, et al. Point-of-care Cepheid Xpert HIV-1 viral load test in rural African communities is feasible and reliable. J Clin Microbiol. 2016;54(12):3050-3055. https://doi.org/10.1128/JCM.01594-16

41. Girdwood SJ, Nichols BE, Moyo C, Crompton T, Chimhamhiwa D, Rosen S Optimizing viral load testing access for the last mile: Geospatial cost model for point of care instrument placement. PLoS One. 2019;14(8):e0221586. https://doi. org/10.1371/journal.pone.0221586

42. Cohen MS, Gay CL, Busch MP, Hecht FM. The detection of acute HIV infection. J Infect Dis. 2010;202(Suppl 2):S270-S277. https://doi.org/10.1086/655651

43. Hecht FM, Wellman R, Busch MP, et al. Identifying the early post-HIV antibody seroconversion period. J Infect Dis. 2011;204(4):526-533. https://doi. org/10.1093/infdis/jir304

44. Parker $E$, Judge $M$, Pastor $L$, et al. Signature of the storm: RNA-seq analysis of the extensive host transcriptome dysregulation caused by acute HIV-1 infection in Mozambican cohort. Abstracts of AIDS 2018; 2018 Jul 23-27; Amsterdam Abstract WEPEA018. Geneva: International AIDS Society; 2018.

45. Pilcher CD, Tien HC, Eron JJ, Jr., et al. Brief but efficient: Acute HIV infection and the sexual transmission of HIV. J Infect Dis. 2004;189(10):1785-1792. https://doi. org/10.1086/386333

46. Wawer MJ, Gray RH, Sewankambo NK, et al. Rates of HIV-1 Transmission pe Coital Act, by stage of HIV-1 infection, in Rakai, Uganda. J Infect Dis. 2005;191(9):1403-1409. https://doi.org/10.1086/429411

47. Powers KA, Ghani AC, Miller WC, et al. The role of acute and early HIV infection in the spread of HIV and implications for transmission prevention strategies in Lilongwe, Malawi: A modelling study. Lancet. 2011;378(9787):256-268. https:// doi.org/10.1016/S0140-6736(11)60842-8

48. Pilcher CD, Price MA, Hoffman IF, et al. Frequent detection of acute primary HIV infection in men in Malawi. AIDS. 2004;18(3):517-524. https://doi.org/10.1097/ 00002030-200402200-00019

49. Fiscus SA, Pilcher CD, Miller WC, et al. Rapid, real-time detection of acute HIV infection in patients in Africa. J Infect Dis. 2007;195(3):416-424. https://doi. org/10.1086/510755
50. Serna-Bolea C, Munoz J, Almeida JM, et al. High prevalence of symptomatic acute HIV infection in an outpatient ward in southern Mozambique: Identification and

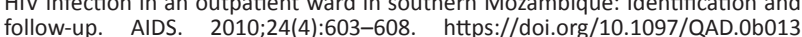
follow-up. A

51. Bebell LM, Pilcher CD, Dorsey G, et al. Acute HIV-1 infection is highly prevalent in Ugandan adults with suspected malaria. AIDS. 2010;24(12):1945-1952. https:// doi.org/10.1097/QAD.0b013e32833bb732

52. Drake AL, Wagner A, Richardson B, John-Stewart G. Incident HIV during pregnancy and postpartum and risk of mother-to-child HIV transmission: A systematic review and meta-analysis. PLoS Med. 2014;11(2):e1001608. https://doi.org/10.1371/ journal.pmed.1001608

53. De Schacht C, Hoffman HJ, Mabunda N, et al. High rates of HIV seroconversion in pregnant women and low reported levels of HIV testing among male partners in Southern Mozambique: Results from a mixed methods study. PLoS One. 2014;9(12):e115014. https://doi.org/10.1371/journal.pone.0115014

54. De Schacht C, Mabunda N, Ferreira OC, et al. High HIV incidence in the postpartum period sustains vertical transmission in settings with generalized epidemics: A cohort study in Southern Mozambique. J Int AIDS Soc. 2014;17(1):18808. https:// doi.org/10.7448/IAS.17.1.18808

55. González R, Rupérez M, Sevene E, et al. Effects of HIV infection on maternal and neonatal health in southern Mozambique: A prospective cohort study after decade of antiretroviral drugs roll out. PLoS One. 2017;12(6):e0178134. https:// doi.org/10.1371/journal.pone.0178134

56. Patel P, Borkowf CB, Brooks JT, Lasry A, Lansky A, Mermin J. Estimating per-act HIV transmission risk: A systematic review. AIDS. 2014;28(10):1509-1519. https://doi. org/10.1097/QAD.0000000000000298

57. Hansasuta $\mathrm{P}$, Rowland-Jones SL. HIV-1 transmission and acute HIV-1 infection. $\mathrm{Br}$ Med Bull. 2001;58(1):109-127. https://doi.org/10.1093/bmb/58.1.109

58. Misra KHJ, Daskalakis D, Udeagu C. editor. Impact of PrEP on drug resistance and acute HIV infection, New York City, 2015-2017. Conference on Retroviruses and Opportunistic Infections; 2019 Mar 04-07. Seattle, WA; 2019.

59. Ananworanich J, Phanuphak N, De Souza M, et al. Incidence and characterization of acute HIV-1 infection in a high-risk Thai population. J Acquir Immune Defic Syndr. 2008;49(2):151-155.

60. Nash M, Huddart S, Badar S, Baliga S, Saravu K, Pai M. Performance of the Xpert HIV-1 viral load assay: A systematic review and meta-analysis. J Clin Microbiol. 2018;56(4):e01673-17. https://doi.org/10.1128/JCM.01673-17

61. Jani IV, Meggi B, Vubil A, et al. Evaluation of the whole-blood Alere Q NAT pointof-care RNA assay for HIV-1 viral load monitoring in a primary health care setting in Mozambique. J Clin Microbiol. 2016;54(8):2104. https://doi.org/10.1128/ JCM.00362-16

62. Pilcher CD, Christopoulos KA, Golden M. Public health rationale for rapid nucleic acid or p24 antigen tests for HIV. J Infect Dis. 2010;201(Suppl 1):S7-S15. https:// doi.org/10.1086/650393

63. Pastor L, Casellas A, Carrillo J, et al. IP-10 Levels as an accurate screening tool to detect acute HIV infection in resource-limited settings. Sci Rep. 2017;7(1):8104 https://doi.org/10.1038/s41598-017-08218-0

64. Powers KA, Miller WC, Pilcher CD, et al. Improved detection of acute HIV-1 infection in sub-Saharan Africa: Development of a risk score algorithm. AIDS 2007;21(16):2237-2242. https://doi.org/10.1097/QAD.0b013e3282f08b4d

65. National Institute of Health (INS), United States Centers for Disease Control (CDC) University of California San Francisco (UCSF), Pathfinder International Population Services International (PSI), Mozambican Association for the Defence of Sexua Minorities (LAMBDA), International Training and Education Center for Health (I-TECH). Final Report: Integrated, biological and behavioral survey among men who have sex with men, Mozambique. San Francisco, CA: UCSF; 2011. Contract No.:U2GPS001468.

66. Mozambique Ministry of Health (MISAU), National Institute of Health (INS) United States Centers for Disease Control (CDC), et al. Final Report: Integrated biological and behavioral survey among people who inject drugs in Mozambique. Maputo: UCSF; 2014

67. National Institute of Health (INS), United States Centers for Disease Control (CDC), University of California San Francisco (UCSF), Pathfinder International Population Services International (PSI), International Training and Education Center for Health (I-TECH). Final Report: Integrated biological and behavioral survey among female sex workers, Mozambique. San Francisco, CA: UCSF; 2011-2012. Contract No.:U2GPSO01468

68. United Nations Office on Drugs and Crime, The Joint United Nations Programme on HIV/AIDS (UNAIDS), The World Bank Group. HIV and prisons in sub-Saharan Africa. Geneva: UNAIDS; 2007

69. Mozambique Ministry of Health (MISAU), National Institute of Health (INS) United States Centers for Disease Control (CDC), et al. Final Report: Integrated survey biological and behavioral analysis among Long Haul truck drivers. Maputo: MISAU; 2012. Contract No.:U2GPS001468.

70. Mozambique Ministry of Health (MISAU), National Institute of Health (INS) Ministry of Labour (MITRAB), United States Centers for Disease Control (CDC), University of California San Francisco (UCSF), International Training and Education Center for Health (I-TECH). Final Report: Integrated biological and behavioral survey among Mozambican workers in the mines of the Republic of South Africa. Maputo: UCSF; 2012. Contract No.:U2GPS001468.

71. International Organization for Migration (IOM). Briefing note on HIV and labour migration in Mozambique. Pretoria: IOM; 2007.

72. De Oliveira T, Kharsany AB, Graf T, et al. Transmission networks and risk of HIV infection in KwaZulu-Natal, South Africa: A community-wide phylogenetic study. Lancet HIV. 2017;4(1):e41-e50. https://doi.org/10.1016/S2352 study. Lancet
3018(16)30186-2 
73. The Joint United Nations Programme on HIV/AIDS (UNAIDS). Country overview Mozambique Geneva [homepage on the Internet] [cited 2020 Jan 4]. Available from: https://www.unaids.org/en/regionscountries/countries/mozambique

74. Republic of Mozambique National Council for the Fight against HIV/AIDS National strategic plan for the response to HIV and AIDS 2015-2019. Maputo: CNCS; 2015.

75. The Joint United Nations Programme on HIV/AIDS (UNAIDS). UNAIDS Data 2019 Eastern and Southern Africa. Geneva: UNAIDS; 2019. Report No.:JC2959E.

76. Abdul-Quader AS, Gouws-Williams E, Tlou S, Wright-De Agüero L, Needle R. Key populations in sub-Saharan Africa: Population size estimates and high risk behaviors. AIDS Behav. 2015;19 (Suppl 1):S1-S2. https://doi.org/10.1007/s10461014-0963-0

77. Demissie M, Johnston LG, Muleta M, et al. Prevalence of HIV and other infections and injection behaviours among people who inject drugs in Addis Ababa, Ethiopia. Afr AIDS Res. 2018;17(3):259-264. https://doi.org/10.2989/16085906.2018.1511604

78. Telisinghe L, Charalambous S, Topp SM, et al. HIV and tuberculosis in prisons in sub-Saharan Africa. Lancet (London, England). 2016;388(10050):1215-1227. https://doi.org/10.1016/S0140-6736(16)30578-5

79. The Joint United Nations Programme on HIV/AIDS (UNAIDS). UNAIDS key population atlas Geneva [homepage on the Internet] [cited 2021 Mar 31]. Available from: https://kpatlas.unaids.org/dashboard
80. Nalá R, Cummings B, Horth R, et al. Men who have sex with men in Mozambique: Identifying a hidden population at high-risk for HIV. AIDS Behav. 2015;19(2):393-404. https://doi.org/10.1007/s10461-014-0895-8

81. Augusto Âdo R, Young PW, Horth RZ, et al. High burden of HIV infection and risk behaviors among female sex workers in three main urban areas of Mozambique. AIDS Behav. 2016;20(4):799-810. https://doi.org/10.1007/s10461-015-1140-9

82. Semá Baltazar C, Horth R, Boothe M, et al. High prevalence of HIV, HBsAg and antiHCV positivity among people who injected drugs: Results of the first biobehavioral survey using respondent-driven sampling in two urban areas in Mozambique. BMC Infect Dis. 2019;19(1):1022. https://doi.org/10.1186/s12879019-4655-2

83. Baral S, Trapence G, Motimedi F, et al. HIV prevalence, risks for HIV infection, and human rights among men who have sex with men (MSM) in Malawi, Namibia, and Botswana. PLoS One. 2009;4(3):e4997. https://doi.org/10.1371/journal. pone.0004997

84. Heijnen M, Mumtaz GR, Abu-Raddad LJ. Status of HIV and hepatitis C virus infections among prisoners in the Middle East and North Africa: Review and synthesis. J Int AIDS Soc. 2016;19(1):20873. https://doi.org/10.7448/ IAS.19.1.20873

85. United Nations, Department of Economic and Social Affairs, Population Division New York, World population prospects 2019 [homepage on the Internet] [cited 2020 Aug 16]. Available from: https://population.un.org/wpp/ 